\title{
Исследование финансовых институтов инновационной инфраструктуры
}

\author{
Павлова И.Г. \\ Белгородский государственный технологический университет им. В.Г. Шухова, \\ Россия, 308012, г. Белгород, ул. Костюкова, 46 \\ E-mail: 79803294873@mail.ru
}

\begin{abstract}
Аннотация. Актуальность данного исследования заключается в необходимости создания финансовых институтов инновационной инфраструктуры в отдельных регионах страны и дальнейшего их развития. Именно финансирование инновационной деятельности позволяет осуществлять использование денежных средств таким образом, чтобы их ориентация производилась исключительно на проектирование, разработку и организацию производства новых видов продукции, а также новой техники и технологий, в том числе и новых организационных форм и методов управления. Цель работы состоит в исследовании финансовых институтов инновационной инфраструктуры. В статье детально представлены основные источники финансирования (государственное финансирование; венчурные фонды и частные инвесторы; банки и инвестиционные компании) и выявлены важные проблемные сегменты российской системы, даны рекомендации по их решению. Полученные результаты вносят вклад в развитие финансовых институтов инновационной инфраструктуры, способствуют выстраиванию правильного вектора их развития с учетом особенностей.
\end{abstract}

Ключевые слова: инновационная инфраструктура, инвестирование, инновация, финансовые институты, источники финансирования.

Благодарности: работа выполнена при поддержке Минобрнауки России в рамках в рамках государственного задания (FZWN - 2020-0016).

Для цитирования: Павлова И.Г. 2021. Исследование финансовых институтов инновационной инфраструктуры. Экономика. Информатика. 48(4): 679-687. DOI: 10.52575/2687-0932-2021-48-4-679-687.

\section{Research of financial institutions of innovative infrastructure}

\author{
Irina G. Pavlova \\ Belgorod State Technological University named after V.G. Shukhov \\ 45 Kostyukov St, Belgorod, 308012, Russia \\ E-mail: 79803294873@mail.ru
}

\begin{abstract}
The relevance of this study lies in the need to create financial institutions of innovative infrastructure in certain regions of the country and their further development. It is the financing of innovative activities that allows the use of funds in such a way that they are focused exclusively on the design, development and organization of production of new types of products, as well as new equipment and technologies, including new organizational forms and management methods. The purpose of the work is to analyze the current state of financial institutions of innovation activity in the Russian Federation and its assessment. The objectives of this study are to form and analyze the main sources of financing for innovation activities, determine the role of financial institutions of innovation infrastructure, and draw conclusions. The study was conducted on the basis of empirical methods of scientific research. The results obtained contribute to the development of financial institutions of innovative infrastructure, contribute to building the right vector of their development, taking into account the peculiarities.
\end{abstract}

Keywords: innovative infrastructure, investment, innovation, financial institutions, sources of financing. 
Acknowledgements: The work is supported by Ministry of education of Russia within the framework of the state task (FZWN - 2020-0016).

For citation: Pavlova I.G. 2021. Research of financial institutions of innovative infrastructure. Economics. Information technologies. 48(4): 679-687 (in Russian). DOI: 10.52575/2687-0932-2021-48-4-679-687.

\section{Введение}

Начиная с 31 января 2020 года, коронавирусная инфекция (COVID - 19) внесла корректировки абсолютно во все сферы жизни человека, тогда инфекция только набирала свои обороты. Несмотря на последствия тяжелой борьбы с коронавирусом в 2021 году, маловероятно предкризисное состояние экономики страны. В первую очередь это связано, например, с величиной совокупного государственного долга (менее $20 \%$ от ВВП), также наблюдается тенденция снижения корреляции между отечественными предприятиями и внешними поставками благодаря политике импортозамещения. При этом с всевозрастающим влиянием пандемии преобразования отразились и на функционировании финансовых институтов инновационной инфраструктуры. Это объясняется активизацией применения интернет-платформ, где происходит непосредственное взаимодействие между продавцом и покупателем, в том числе все организации в срочном порядке должны перейти на дистанционный формат работы с применением различных технологий. Вследствие этого произошел резкий скачок в трансформации традиционного формата деятельности на инновационно-технологический.

Развитие социально-экономической системы Российской Федерации формируется в большей степени за счет наращивания инновационного потенциала, а также стимулирования инновационной деятельности. Главной целью любой страны выступает обеспечение стабильного социально-экономического развития в рамках быстроизменяющегося внешнеэкономического положения страны, возрастающей конкуренции, в том числе с учетом императивов перехода к шестому технологическому укладу [Бережная, Павлова, Сотникова, 2019].

В большинстве стран наиболее важными акторами в процессе формирования и внедрения на рынок инноваций относительно микроуровня выступают предприятия, тестирующие высокоэффективные формы межфирменного взаимодействия и кооперации. При этом важно осуществление государственной политики, стратегической целью которой является стимулирование инновационной активности компаний и создание для этого наиболее благоприятных рамочных условий [Дорошенко, Ряпухина, 2019]. Одно из таких условий - развитая инфраструктура инновационной деятельности, включая институты поддержки инноваций, обеспечивающие интеграцию и согласование усилий основных участников этой деятельности (бизнес-инкубаторы, разные виды кластеров и т. д.) [Павлова, 2019].

Инновационная инфраструктура трактуется как определенная система тесно связанных между собой структур, которые обслуживают и обеспечивают осуществление инновационной деятельности. От того, как будет реализовываться функционирование инновационной инфраструктуры, будет зависеть темп осуществления инновационных трансформаций в экономике, включая их стоимость и эффективность [Верхотурова, 2010]. Автор определяет инновационную инфраструктуру как комплекс взаимосвязанных институтов, деятельность которых направлена на обеспечение доступа к различным ресурсам, формирующим в свою очередь благоприятные условия, при этом осуществляющим поддержку участникам инновационной деятельности. На основании данного определения можно вычленить основные группы институтов, благодаря которым создается инновационная инфраструктура, их система представлена ниже на рисунке 1. 


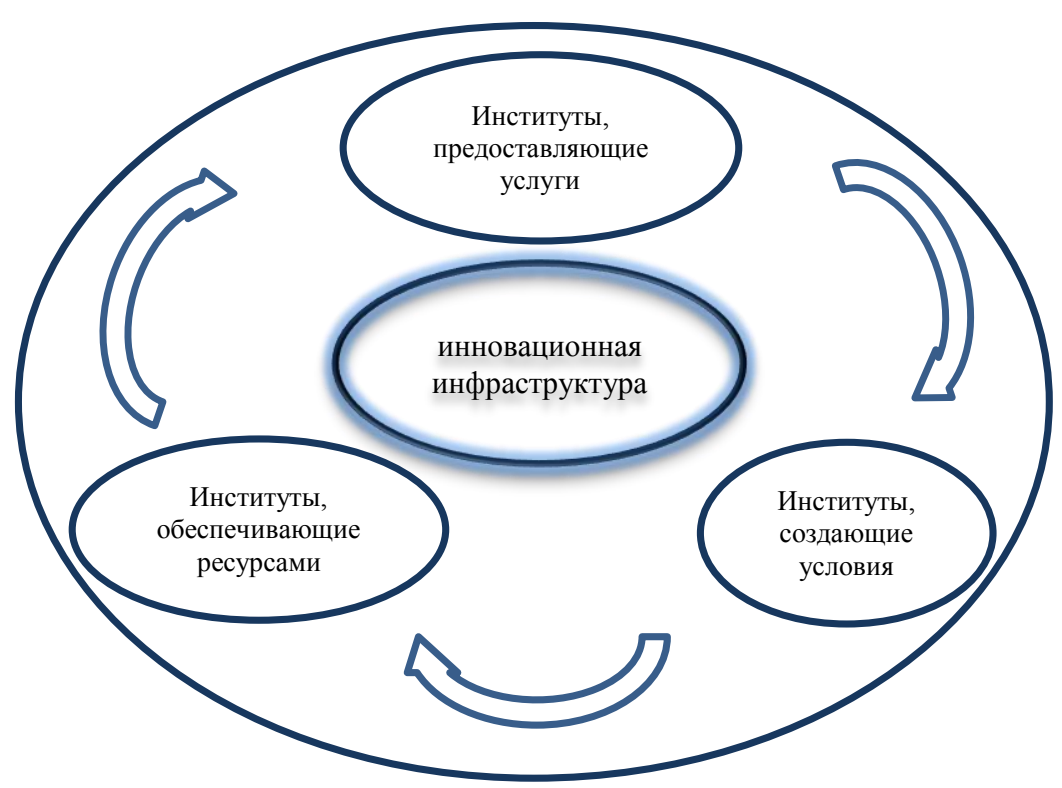

Рис. 1. Комплексный подход к определению инновационной инфраструктуры

Fig. 1. An integrated approach to the definition of innovation infrastructure

В группу институтов, обеспечивающих ресурсами инновационную инфраструктуру, относят финансово-кредитные и кадровые институты. Институты, предоставляющие услуги: сбытовые и информационно-консалтинговые институты. В последнюю группу - институты, создающие условия - следует отнести правовой и производственно-технологические институты. Но центральная роль отводится именно финансовым институтам, так как они обеспечивают инновационное развитие через предоставление необходимых финансовых ресурсов, без которых не представляется возможным полноценное функционирование инновационного развития, в том числе и инновационной инфраструктуры.

В экономике Российской Федерации отмечается особая роль государства касаемо финансирования науки. Так, например, за рубежом в становлении инновационной инфраструктуры непосредственно принимает участие частный сектор в течение долгого периода времени. Что касается Российской Федерации, страна утратила значительную часть своего научного потенциала, поэтому во многих областях необходимо создавать инновационную инфраструктуру вновь.

\section{Объекты и методы исследования}

Объектами исследования являются особенности функционирования финансовых институтов инновационной инфраструктуры. Обозначена важность и значительность проводимого исследования, осуществлено ее обоснование. Рассматриваются основные источники финансирования инновационной деятельности и произведен их анализ. Выявлены важные проблемные сегменты российской системы, одним из которых является отсутствие особых центров компетенций по инновациям и цифровым технологиям. Представлены предложения автора по выявленным проблемам.

При исследовании применялись методы логического анализа, обобщения и синтеза, в том числе экономико-статистические методы обработки цифровой информации.

\section{Результаты и их обсуждение}

Важное место в развитии инновационной инфраструктуры занимают ее финансовые институты. Основные источники финансирования инновационной деятельности инновационных проектов, реализующиеся предприятием, - заемные и собственные средства. 
В первую группу входят кредиты, которые выдаются как коммерческими предприятиями, так и банками. Вторая группа включает в себя прибыль предприятия, выручку от реализации нематериальных активов и страховое возмещение убытков.

Роль финансовых институтов инновационной инфраструктуры заключается в ослаблении доступа инновационных предприятий к заемным средствам [Верхотурова, 2009]. Внешнее финансирование инновационной деятельности можно представить в виде следующих источников финансирования:

1. государственное финансирование;

2. венчурные фонды и частные инвесторы;

3. банки и инвестиционные компании.

Государственная поддержка осуществляется за счет венчурного или прямого финансирования инновационного проекта следующим образом: вложение ценных бумаг (иное имущество) в объекты предпринимательской и иной деятельности для получения прибыли и достижения полезного эффекта и в других формах финансового обеспечения в соответствии с законодательством Российской Федерации [Андрюшин, Карминский, 2021]. В целях поддержки инновационных проектов приоритетных направлений функционирует Федеральный фонд фундаментальных исследований (ФФФИ), функцией которого выступает организационнофинансовое обеспечение проектов. В то же время вектор деятельности данного фонда направлен на становление системы взаимосвязей актантов инновационной деятельности, развитие их взаимодействия для коллективной реализации научно-исследовательских работ, формирование общих стратегических целей [Малыхина, Бережная, 2019].

На основании представленных данных в статистическом сборнике Высшей школы экономики можно выявить динамику такого показателя, как затраты на инновационную деятельность из средств бюджета в Центральном федеральном округе (рис. 2).

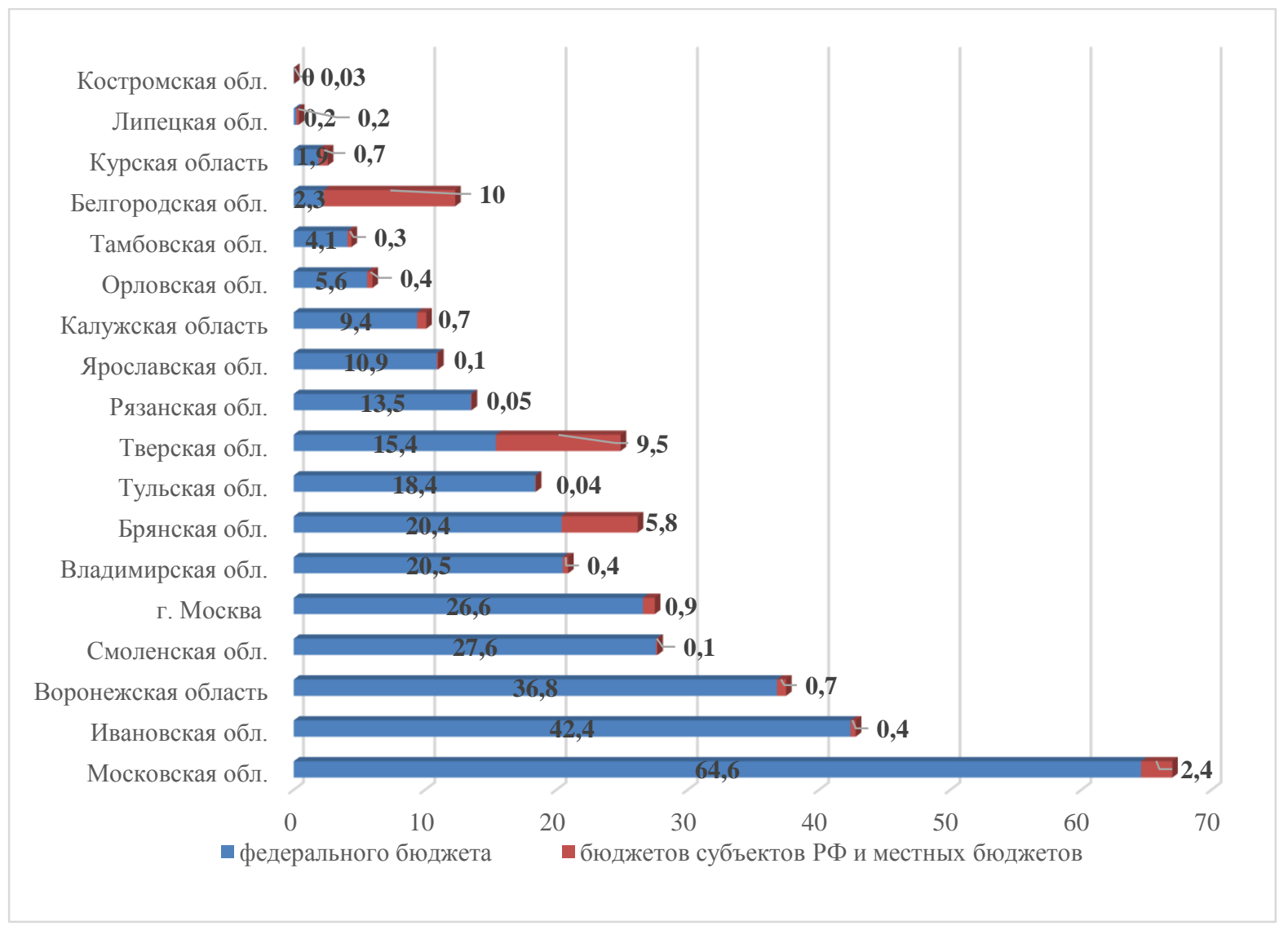

Рис. 2. Затраты на инновационную деятельность из средств бюджета в ЦФО за 2019 год, \% Fig. 2. Costs of innovation activities from the budget in the Central Federal District for 2019, \% 
Так, наблюдается неравномерная динамика в отношении данного показателя из федеральных средств: максимальное значение присуще Московской области $(64,6)$, минимальное - Липецкой области $(0,2)$ [Индикаторы инновационной деятельности: 2021 : статистический сборник, 2021]. Однако ситуация по финансированию из бюджетов субъектов РФ и местных бюджетов иная - наблюдается более равномерное значение исследуемого показателя во всех областях ЦФО.

Такая тенденция объясняется структурными особенностями научноисследовательского комплекса РФ. Стоит отметить, что значительная доля затрат на науку характерна, как было отмечено ранее, государству, при этом она же пропорциональна государственному контролю над научным сектором, что вполне обосновано. Также сложившаяся тенденция не в полной мере активизирует научно-исследовательскую деятельность на итоговый результат, что в целом не способствует наращиванию инновационной активности предприятий.

Финансирование из средств бюджета страны является ключевым источником, способствующим решению масштабных научно-технических проблем [Himmel, Siemiatycki, 2017]. Государственная помощь в поддержке инновационной деятельности может выражаться в двух направлениях:

1. прямое финансирование - финансовая помощь централизованными ресурсами;

2. косвенное финансирование - мобилизация средств за счет привлечения рыночного механизма.

При этом государственная поддержка в финансировании инновационной деятельности может реализовываться через бюджетные и внебюджетные фонды финансирования НИР и ОКР. Фонды, которые выделяют финансовые средства из бюджета страны, считаются некоммерческими и предоставляют в распоряжение средства на безвозвратной основе [Малыхина, Брежнев, Божков, 2019].

Именно бюджетные ассигнования являются главным инструментом финансирования научно-исследовательских работ в Российской Федерации, они и составляют большую часть из федерального бюджета. Меньшую часть ассигнований представляют отчисления в целевые бюджетные фонды и финансирование НИР по приоритетным направлениям развития науки и техники. Данные средства выделяются по результатам конкурса в целях разработки приоритетных инновационных проектов.

Венчурное финансирование осуществляется инвестиционными компаниями без гарантий возврата инвестиций, но, однако, большим риском и сверхприбылью в случае успеха инноваций. На фоне всеобщей экономической стагнации в связи с коронавирусной инфекцией COVID - 19 и падения многих финансовых рынков динамика роста венчурных инвестиций за последние пару лет ярко контрастирует своей масштабностью и маржинальностью. Таким образом, данные тенденции венчурного сегмента привлекают внимание профильных инвесторов из других ниш, что вносит свои корректировки и оптимизацию в классические схемы венчурных фондов. В РФ функционируют 189 организаций, занимающихся прямыми инвестициями по состоянию на 2021 год (совершены вложения в 185 крупномасштабных стартапов). Венчурный капитал в РФ сегодня составляет около 4,2 миллиардов долларов [Зайцев, 2020].

В Российской Федерации, как и в мире в целом, слабо развито частное инвестирование. Под данным термином следует понимать официальную структуру или физическое лицо, которые инвестируют капитал в дальнейшее развитие крупных проектов. Количество частных инвесторов в РФ за май 2021 года увеличилось на 561,1 тысяч человек до 12,2 миллионов человек [Смирнов, Родионов, 2014]. Согласно данным статистического сборника Высшей школы экономики, только за май 2021 года частные инвесторы вложили: в российские акции 32 млрд рублей, в облигации - 59,8 млрд рублей, в биржевые фонды (БПИФы и ЕТF) 8,4 млрд рублей. 
Средства банков и инвестиционных компаний привлекаются в целях финансирования инноваций любых предприятий. Отличительная черта - период финансирования, который не должен превышать период реализации инновации. К данной группе можно отнести также финансовый лизинг, который используется в случае покупки дорогостоящего оборудования как важного элемента инновационного проекта. Благодаря инновационному лизингу совершенствуется инновационный процесс, он ткакже содействует росту конкурентоспособности и позволяет финансовому состоянию предприятия выйти на новый уровень [Sengupta, 2021]. Самыми инвестиционными компаниями в РФ являются: «Тинькофф Инвестиции» - в 2016 году Тиньков Банк запустил площадку для частных инвесторов, с помощью которой можно совершать сделки на Мосбирже и зарубежных [Официальный сайт Тинькофф Инвестиции]; ООО ИК «Фридом финанс» [Официальный сайт инвестиционной компании «Фридом Финанс»]; ООО «Открытие брокер» [Официальный сайт ООО «Открытие брокер»]; ООО УК «Альфа-Капитал» [Официальный сайт ООО УК «Альфа-Капитал»]; ООО «Управляющая компания «Финам Менеджмент» [Официальный сайт управляющей компании «Финам Менеджмент»].

Таким образом, рассмотренные выше финансовые институты инновационной инфраструктуры играют важную роль в развитии экономики страны. Финансовые институты оказывают непосредственное влияние на трансформацию инновационной инфраструктуры, соответственно воздействуют и на становление и развитие инновационных структур (которые являются неотьемлемой частью инновационной инфраструктуры). Российская Федерация на сегодняшний день мало акцентирует внимание на создании особых центров компетенций по инновациям и цифровым технологиям, хотя в других странах это распространено и развивается. В целях нейтрализации выявленной проблемы необходимо обратить внимание на формирование развитых платформ, технологий, институциональной и инфраструктурной сред, что позволит российской экономике сократить значительный разрыв в развитии по сравнению с развитыми странами, где активно применяются и используются цифровые технологии и центры компетенций по инновациям в различных сферах деятельности. Например, если рассматривать цифровые технологии, они могут выступать в качестве новых усовершенствованных технологий - использование компонентов робототехники и сенсорики, а также технологий виртуальной и дополненной реальностей и т. п.

Относительно центров разработки инноваций, они присутствуют абсолютно во всех высокотехнологичных компаниях, входящих в АФК «Система». Так, например, в «МТС», кроме центров компетенций, есть и собственные акселераторы как для внутренних, так и для внешних инновационных проектов, способствующих наращиванию экосистемы цифровых сервисов компании. «Технологическая площадка» характерна для такой компании, как «Мегафон». По своей сути она представляет площадку для проверки гипотез, реализации пилотов со стартапами и внедрения инновационных решений. Результат ее практической реализации - свыше 100 пилотных проектов, относящихся к девяти важным кластерам развития компании.

Инвестиционные компании в целях оценки инновационной деятельности опираются, главным образом, на объем инвестиций, прирост выручки и прибыли благодаря инновациям, финансовые метрики (IRR, ROI, NPV и др.), объем внедренных инновационных проектов на предприятии [Doroshenko, Malykhina, Somina, 2019].

Таким образом, для того, чтобы идея перешла на стадию «продукт» либо на совершенно новое направление бизнеса, необходимы большие усилия, следовательно, для успеха инноваций важно планировать бюджеты для исследования гипотез. Например, «Микрон» - один из самых крупных российских производителей микроэлектронной продукции, именно в этой компании любой сотрудник вправе инициировать проект и получить денежное вознаграждение. Деятельность, связанная с инновациями, для сотрудников очень выгодна, несмотря на любую систему мотивации. Во-первых, в большинстве случаев это имеет положительный эффект в виде материального 
вознаграждения. Во-вторых, перед сотрудником предприятия открываются карьерные перспективы.

Мобилизация инвестиций в инновационную деятельность представляет собой важную задачу, стоящую перед РФ, так как для развития высокоперспективных проектов требуется финансирование, которое в большинстве случаев недоступно. Для нейтрализации такого барьера Правительство РФ осуществляет комплексную работу, ориентированную на совершенствование условий на предмет привлечения инвестиций в инновационный сектор экономики. Центральная роль в активизации мобилизации финансирования в инновационный сектор экономики отведена системе институтов инновационного развития (АО "РОСНАНО", Фонд развития Центра разработки и коммерциализации новых технологий и др.). Институты развития выступают в качестве катализаторов частных инвестиций в приоритетных секторах и отраслях экономики и формируют условия для становления инновационной инфраструктуры, которая оснащает предприятия требуемыми финансовыми и информационными ресурсами.

\section{Заключение}

Финансовые институты инновационной инфраструктуры представляют огромную ценность в отношении финансирования инновационной деятельности, где аккумулируются финансовые средства и распределяются на ключевые направления инновационных процессов. В ходе проведенного исследования раскрыто понятие инновационной инфраструктуры и представлен комплексный подход к ее определению. В результате было выявлено, что на формирование инновационной инфраструктуры оказывает влияние группа институтов, где именно финансовые институты занимают доминирующее положение, выступая в качестве основы для создания инновационной инфраструктуры.

Развитие финансовых институтов инновационной инфраструктуры позволит решить следующие актуальные задачи, стоящие перед российской экономикой: создание условий для максимально быстрого и эффективного внедрения инноваций во всех отраслях страны, наращивание стратегического инновационного потенциала в приоритетных направлениях развития, формирование благоприятных условий для поддержки и расширения кадрового потенциала науки и предотвращение утечки профессиональных кадров из инновационной сферы.

\section{Список источников}

1. Зайцев Д.А. 2020. Отчет о результатах экспертно-аналитического мероприятия «Анализ механизмов венчурного и прямого инвестирования, осуществляемого с использованием средств федерального бюджета». URL: https://ach.gov.ru/upload/iblock/a29/a298f3e07b401a8d60e4e4afdd1 671b7.pdf (дата обращения: 14.08.2021).

2. Индикаторы инновационной деятельности: 2021: статистический сборник / Л.М. Гохберг, Г.А. Грачева, К.А. Дитковский и др.; Нац. исслед. ун-т «Высшая школа экономики». - М.: НИУ ВШЭ, 2021. - 280 с. - 250 экз. - ISBN 978-5-7598-2375-9.

3. Официальный сайт инвестиционной компании «Фридом Финанс». [Электронный ресурс]. URL: https://ffin.ru/ (дата обращения: 01.08.2021).

4. Официальный сайт ООО «Открытие брокер». [Электронный ресурс]. URL: https://openbroker.ru/invest/ (дата обращения: 04.08.2021).

5. Официальный сайт OOO УК «Альфа-Капитал». [Электронный ресурc]. URL: https://www.alfacapital.ru/ (дата обращения: 03.08.2021).

6. Официальный сайт Тинькофф Инвестиции. [Электронный ресypc]. URL: https://www.tinkoff.ru/invest/ (дата обращения: 03.08.2021).

7. Официальный сайт управляющей компании "Финам Менеджмент". [Электронный ресурс].

URL: https://www.finam.ru/about/CompanyStructure003E8/ (дата обращения: 03.08.2021).

8. Рейтинг высокодоходных инвестиционных компаний 2021 года. [Электронный ресурс]. URL: https://finansy.name/rejting-investicionnyh-kompanij (дата обращения: 03.08.2021). 
9. Федеральный закон "О науке и государственной научно-технической политике" от 23.08.1996 N 127-Ф3. [Электронный pecypc]. URL: http://www.consultant.ru/document/cons_doc_ LAW_11507/ (дата обращения: 03.08.2021).

\section{Список литературы}

1. Андрюшин С.А., Карминский А.М. 2021. Современные финансовые институты и рынки, их регулирование в кризисных условиях: международный опыт и российская практика (обзор выступлений участников тематической конференции «Банки и финансовые рынки» Четвертого Российского экономического конгресса). Вестник Института экономики РАН, 2: 182-197.

2. Бережная А.В., Павлова И.Г., Сотникова А.А. 2019. Оценка и перспективы развития инвестиционно-инновационного потенциала Белгородской области. Пространственное развитие территорий: сборник научных трудов II Международной науч.-практ. конф., Белгород: ООО «ЭПИЦЕНТР»: 42-50.

3. Верхотурова Т.А. 2009. Место и роль финансовых институтов в инновационной инфраструктуре России. Налоги и финансы, 3: 15-19.

4. Верхотурова Т.А. 2010. Развитие финансовых институтов инновационной инфраструктуры России. Известия СПбГЭУ, 3: 75-77.

5. Дорошенко Ю.А., Ряпухина В.Н. 2019. Анализ региональных моделей инновационного развития в контурах политики неоиндустриализации. Вестник Саратовского государственного социально-экономического университета, 4 (78): 47-51.

6. Малыхина И.О., Бережная А.В. 2019. Анализ принципов организации и способов стимулирования инновационной деятельности регионов. Белгородский экономический вестник, 2 (94): 57-61.

7. Малыхина И.О., Брежнев А.Н., Божков Ю.Н. 2019. Влияние инфраструктурной поддержки на формирование и стимулирование инновационно-инвестиционных источников экономического развития региона. Евразийский международный научно-аналитический журнал «Проблемы современной экономики», 2: 131-134.

8. Павлова И.Г. 2019. Анализ динамики развития инновационной инфраструктуры в Белгородской области. Актуальные аспекты фундаментальных и прикладных исследований»: всероссийская научно-практическая конференция научно-педагогических работников общего и профессионального образования. Орёл: ОрелГУЭТ: 45-49.

9. Смирнов А.Л., Родионов И.И. 2014. Финансовые институты развития и управление инновациями (некоторые Актуальные вопросы). Финансовая аналитика: проблемы и решения, 46: 11-17.

10.Doroshenko Y.A., Malykhina I.O., Somina I.V. 2019. Methodology of the formation of a comprehensive support mechanism of innovation and investment development in the region. 9th International Conference "Economics and Management-Based on New Technologies" (EMoNT-2019), Vrnjacka Banja, Serbia. pp. 155-158.

11.Himmel M, Siemiatycki M. 2017. Infrastructure public-private partnerships as drivers of innovation? Lessons from Ontario, Canada. Environment and Planning C: Politics and Space. 35(5):746764. doi:10.1177/2399654417701430

12.Sengupta A. 2021. New Realms of Influence: Infrastructure Development, Financial Institutions and Markets. International Studies. doi:10.1177/00208817211028043

\section{References}

1. Andryushin S.A., Karminsky A.M. 2021. Modern financial institutions and markets, their regulation in crisis conditions: international experience and Russian practice (review of presentations by participants of the thematic conference "Banks and Financial Markets" of the Fourth Russian Economic Congress). Bulletin of the Institute of Economics of the Russian Academy of Sciences, 2: 182-197. (in Russian)

2. Berezhnaya A.V., Pavlova I.G., Sotnikova A.A.2019. Assessment and prospects for the development of the investment and innovation potential of the Belgorod region. Spatial development of territories: collection of scientific papers of the II International Scientific and Practical Conference. Belgorod: OOO “EPICENTER": 42-50. (in Russian)

3. Verkhoturova T. A. 2009. The place and role of financial institutions in the innovation infrastructure of Russia. Taxes and finance, 3: 15-19. (in Russian) 
4. Verkhoturova T. A. 2010. Development of financial institutions of innovative infrastructure in Russia. Izvestiya SpBGETU, 3: 75-77. (in Russian)

5. Doroshenko Yu.A., Ryapukhina V.N. 2019. Analysis of regional models of innovative development in the contours of the neoindustrialization policy. Bulletin of the Saratov State Socio-Economic University, 4 (78): 47-51. (in Russian)

6. Malykhina I.O., Berezhnaya A.V. 2019. Analysis of the principles of organization and ways to stimulate innovative activity of regions. Belgorod Economic Bulletin, 2 (94): 57-61. (in Russian)

7. Malykhina I.O., Brezhnev A.N., Bozhkov Yu.N. 2019. The impact of infrastructure support on the formation and stimulation of innovation and investment sources of economic development of the region. Eurasian International Scientific and Analytical Journal "Problems of Modern Economy", 2: 131-134. (in Russian)

8. Pavlova I.G. 2019. Analysis of the dynamics of innovation infrastructure development in the Belgorod region. Actual aspects of fundamental and applied research": All-Russian scientific and practical conference of scientific and pedagogical workers of general and vocational education. Eagle: EagleGUIT: 45-49. (in Russian)

9. Smirnov A.L., Rodionov I.I. 2014. Financial institutions of development and innovation management (some Topical issues). Financial analytics: problems and solutions, 46: 11-17. (in Russian)

10.Doroshenko Y.A., Malykhina I.O., Somina I.V. 2019. Methodology of the formation of a comprehensive support mechanism of innovation and investment development in the region // 9th International Conference "Economics and Management-Based on New Technologies" (EMoNT-2019), Vrnjacka Banja, Serbia. pp. 155-158.

11.Himmel M, Siemiatycki M. 2017. Infrastructure public-private partnerships as drivers of innovation? Lessons from Ontario, Canada. Environment and Planning C: Politics and Space. 35 (5):746764. doi:10.1177/2399654417701430.

12.Sengupta A. 2021. New Realms of Influence: Infrastructure Development, Financial Institutions and Markets. International Studies. doi:10.1177/00208817211028043.

Конфликт интересов: о потенциальном конфликте интересов не сообщалось.

Conflict of interest: no potential conflict of interest related to this article was reported.

\section{ИНФОРМАЦИЯ ОБ АВТОРЕ}

Павлова Ирина Геннадьевна, ассистент кафедры стратегического управления института экономики и менеджмента Белгородского государственного технологического университета имени В.Г. Шухова, г. Белгород, Россия

\section{INFORMATION ABOUT THE AUTHOR}

Irina G. Pavlova, Assistant of the Department of Strategic Management, Institute of Economics and Management, Belgorod State Technological University named after V.G. Shukhov, Belgorod, Russia 